\title{
Modeling meso-scale-void formation during through-thickness flow in liquid composite molding
}

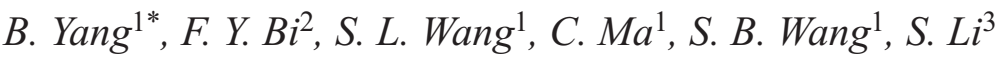 \\ ${ }^{1}$ State Key Laboratory of Mechanical Transmission, Chongqing University, Chongqing, China \\ ${ }^{2}$ School of Mechatronics Engineering, Heilongjiang Institute of Technology, Harbin, China \\ ${ }^{3}$ Beijing Aerospace XinFeng Mechanical Equipment Co. Ltd., Beijing, China
}

Received 7 May 2019; accepted in revised form 18 July 2019

\begin{abstract}
Void formation during in-plane flow has been widely researched, while the void prediction method for throughthickness flow has not been reported, which restricts the effective quality control for through-thickness permeating type liquid composite molding (LCM). In this paper, the structural morphology and connectivity of mesopores in multi-layer woven fabrics have been studied, the difference between intra-yarn and inter-yarn flow paths during through-thickness permeating has been analyzed, and the air entrapment processes in different types of mesopores have been revealed. Based on the modeling of micro and meso through-thickness flow, a mathematical model to predict the formation and size of mesoscale-void has been established, the variation of intra-yarn flow path under different compaction conditions has been analyzed to guarantee the precision of the model. Experimental method has been designed to measure the size of meso-scale-void formed during through-thickness LCM, comparisons between prediction and experimental results have demonstrated the correctness of the above model.
\end{abstract}

Keywords: polymer composites, liquid composite moulding, through-thickness flow, void formation, analytical modelling

\section{Introduction}

Since the adaptability of complex structure with largescale and remarkable low-cost advantage, liquid composite molding (LCM) has been gaining popular attention and applications [1]. During LCM, various problems may be produced, such as void, dry spot, washing out and so on. Among all types of problems, void type defect is the most common, and it significantly reduces mechanical properties of the composite products[2, 3]. Previous studies showed that every 5 percent increase in void content is associated with a 20 percent fall in inter-laminar shear strength of composite part [4-6]. Therefore, the maximum permissible void content of composite structure is $2 \%$ according to the American Aeronautics Standard [7]. In the mold-filling process of LCM, the liquid resin is injected into the mold under pressure to infiltrate the pre-placed preform. The commonly used fabric preform has a typical hierarchical structure, fabric is interlaced by a lot of yarns with millimeter-sized sections, and yarn is composed of thousands of filaments with micrometer-sized sections. As a result, the millimeter-sized mesopores and micrometer-sized micropores are formed between and inside yarns, respectively, resin flow in preform can be accordingly divided into meso flow in mesopores and micro flow in micropores. The driving force of resin flow in preform mainly consists of capillary force and hydrodynamic force, the flow resistance is generated from viscous drag. In mesopores, capillary force is negligible since the mesopores have relatively large sizes, so the hydrodynamic force is the primary drive force of the meso flow and the meso flow resistance is small. In micropores, capillary force is more important, and

${ }^{*}$ Corresponding author, e-mail: yangbo61@cqu.edu.cn (C) BME-PT 
the micro flow resistance is high. The differences in capillary force and flow resistance between mesopores and micropores are usually several orders of magnitude. Hence the non-uniformity of flow front between meso flow and micro flow may occur, and void will be formed if air is entrapped $[8,9]$. Air entrapment in micropores occurs when the global resin flow velocity is high, in this case, micro flow is left behind since the enormous flow resistance in micropores. Meso-scale-void will be formed when the global resin flow velocity is low, in this case, micro flow is leading since the capillary force inside yarns is much bigger than hydrodynamic force.

Once voids are formed during mold-filling, it is difficult to eliminate them completely [10]. Therefore, studying the influence of preform structure and moldfilling parameters on void creation, and optimizing the process parameters to avoid or reduce the void formation become a significant method to improve the product quality of LCM. So far, a large number of researches have been implemented on the modeling and prediction of void formation during LCM. From a series of experiments, early studies [11-14] suggested that void content of LCM part is related to the modified capillary number $\left(\mathrm{Ca}^{*}\right)$ as shown in Equation (1):

$$
C a^{*}=\frac{\mu \bar{u}}{\gamma \cos \theta}
$$

where $\mu$ is the resin viscosity, $\gamma$ is the surface tension of resin, $\theta$ is the contact angle between resin and fibers, and $\bar{u}$ is the global resin velocity. This model has been successfully applied in the optimization of mold-filling parameters of LCM [15-18], while the disadvantages of high cost, low efficiency and poor universality produce great limitations on the wide application of experimental research method, so the theoretical analysis method has been getting a lot of attention from researchers. Hu et al. [19] analyzed the characteristics of microscopic pores and built a mathematical model to predict the void formation during the in-plane impregnation of LCM process, numerical simulations and experiments were implemented to verify the above model. Lee et al. [20] built a mathematical model to predict the void formation by analyzing the velocity difference between micro and meso flows, then they used the model in the realtime control of resin flow during RTM process. Schell et al. [21] presented a mathematical model of mesoscale-void generation, experimental validation has been conducted to verify the model. Gourichon et al [22] developed a bidirectional void prediction model based on entrapment angle analysis, a radial flow experiment was conducted to validate the developed model. Park et al. [7] presented a model to address the void formations in mesopores as well as in micropores. Matuzaki and coworkers [23, 24] constructed a mathematical model for meso-scale-void formation in a geometrically anisotropic woven fabric, the model has been applied to calculate the minimumvoid angle for radial injection LCM. Yang and coworkers $[25,26]$ studied the influence of flow direction, fabric shear and inter layer shift on the inplane air entrapment during LCM, void prediction models on different conditions were established and validated by experiments. With the development of computer simulation technology, some scholars began to explore the numerical simulation methods of void formation during LCM [27-29], while two-dimensional cross-sections or simplified models of preform were usually adopted because of the complexity and multi-scale characteristics of the fabric structure, the prediction accuracy was inevitably degraded.

Recently through-thickness permeating type LCM processes, such as Vacuum-Assisted Resin Transfer Molding (VARTM), Compression Resin Transfer Molding (CRTM) and Resin Film Infusion (RFI), have become increasingly popular due to their rapid and high-quality mold-filling and low cost by employing single-side mold [30, 31]. However, it is evident from literature analysis that no study has been devoted to the void formation during through-thickness flow, which greatly hinders their application area. In this paper, the structural morphology and connectivity of mesopores in multi-layer woven fabrics were analyzed, the micro/meso flow paths and air entrapment process during resin through-thickness flow were studied. Based on the analyses of micro and meso flow velocities, a mathematical model for prediction of meso-scale-void formation during through-thickness permeating type LCM was established. A series of experiments were implemented to identify the validity of the presented model.

\section{Analyses of air entrapment during through-thickness permeating}

Two types of mesopores can be found in a one-layer woven fabric, respectively are mesopore I and mesopore II as shown in Figure 1a and 1b. Mesopore I 
penetrates the unit-cell on the through-thickness direction, its height $h_{\mathrm{pI}}$ is equal to the thickness of the unit-cell ${ }_{\mathrm{h}}$ as shown in Figure 1b. Mesopore II locates above and below yarns, its height is $h / 4$ as shown in Figure 1b. In multi-layer fabrics, if all the fabric layers are aligned with each other, that is, there is no nesting between fabric layers as shown in Figure 1c, mesopores will connect to each other on the thickness direction to form bigger pores. The height of mesopore I $h_{\mathrm{pI}}$ increases continuously with the increase of layer number $n$ since the connected mesopore I can be infinite and $h_{\mathrm{pI}}=n \cdot h$. While the maximum height of mesopore II is only $h / 2$ since the maximal connection number of mesopore II is 2 .
In the actual project, fabric layers are usually laid up randomly, in-plane relative shifts occur between fabric layers. Figure 2 shows the effect of in-plane relative shift on the through-thickness connection of mesopore I. Mesopore 1 shown in Figure 2a is a three-layer connected mesopore I, its shape changes with the in-plane shift of Layer 3. When the in-plane shift of Layer 3 is small, the connection path of mesopore 1 will distort but maintain integrity as shown in Figure 2b. With the increase of in-plane shift, Layer 3 will contact with Layer 2 and Layer 4 at the contact points shown in Figure 2c, and mesopore 1 will be broken into three disconnected mesopores, respectively are mesopore 2,3 and 4 . The

a)
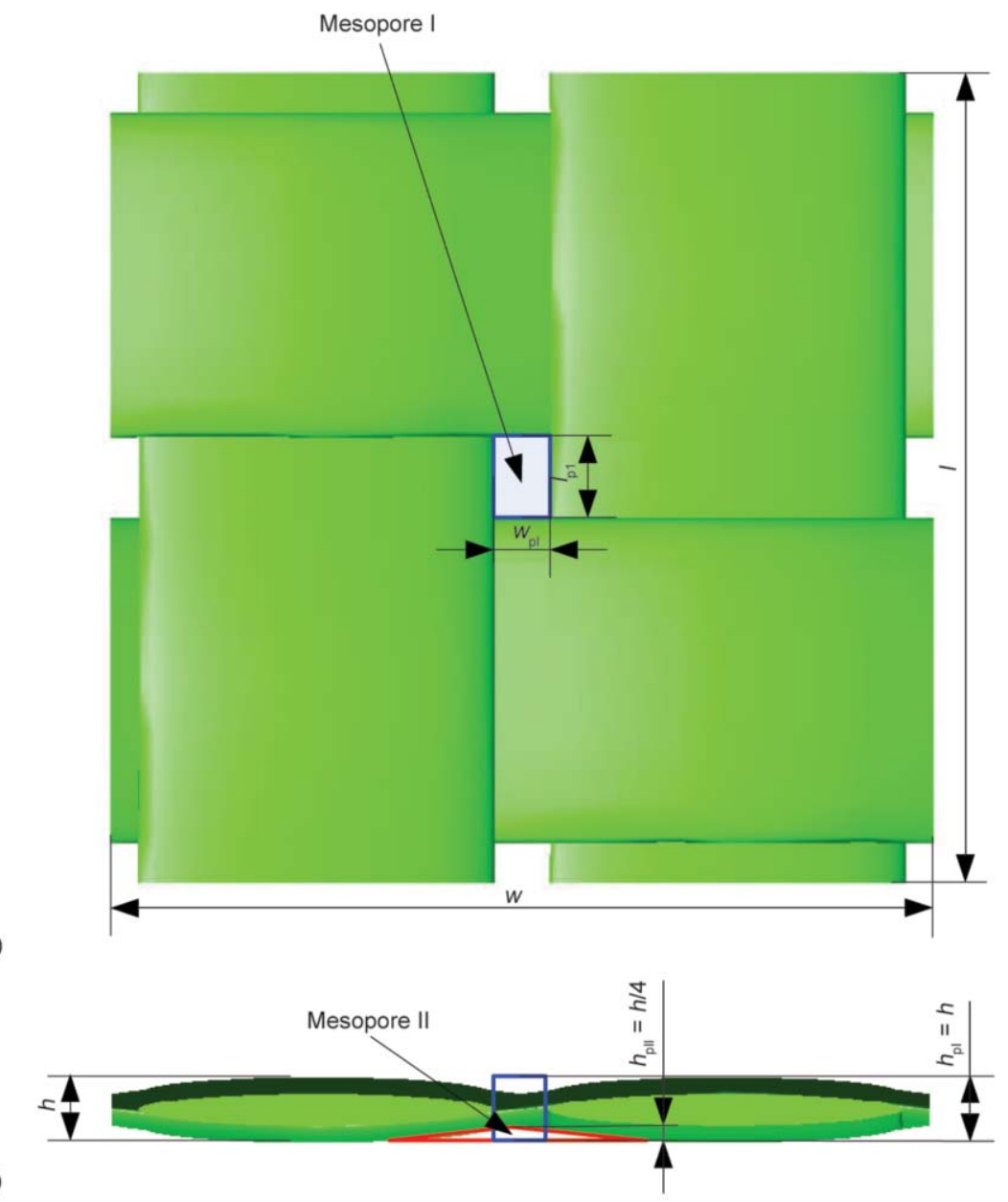

b)

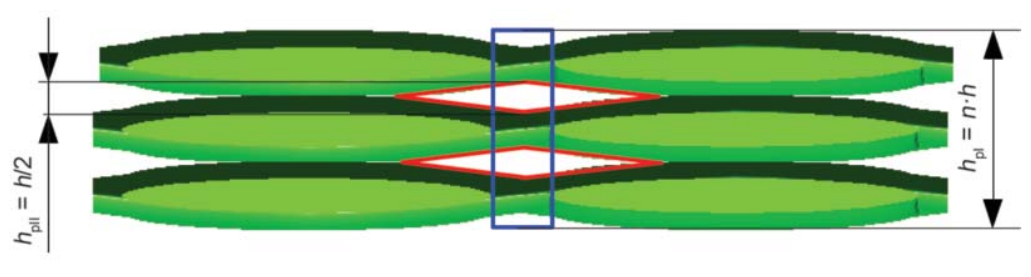

Figure 1. Mesopores and their through-thickness connection in woven fabrics. a) mesopore I, b) mesopore II, c) throughthickness connection of mesopores. 

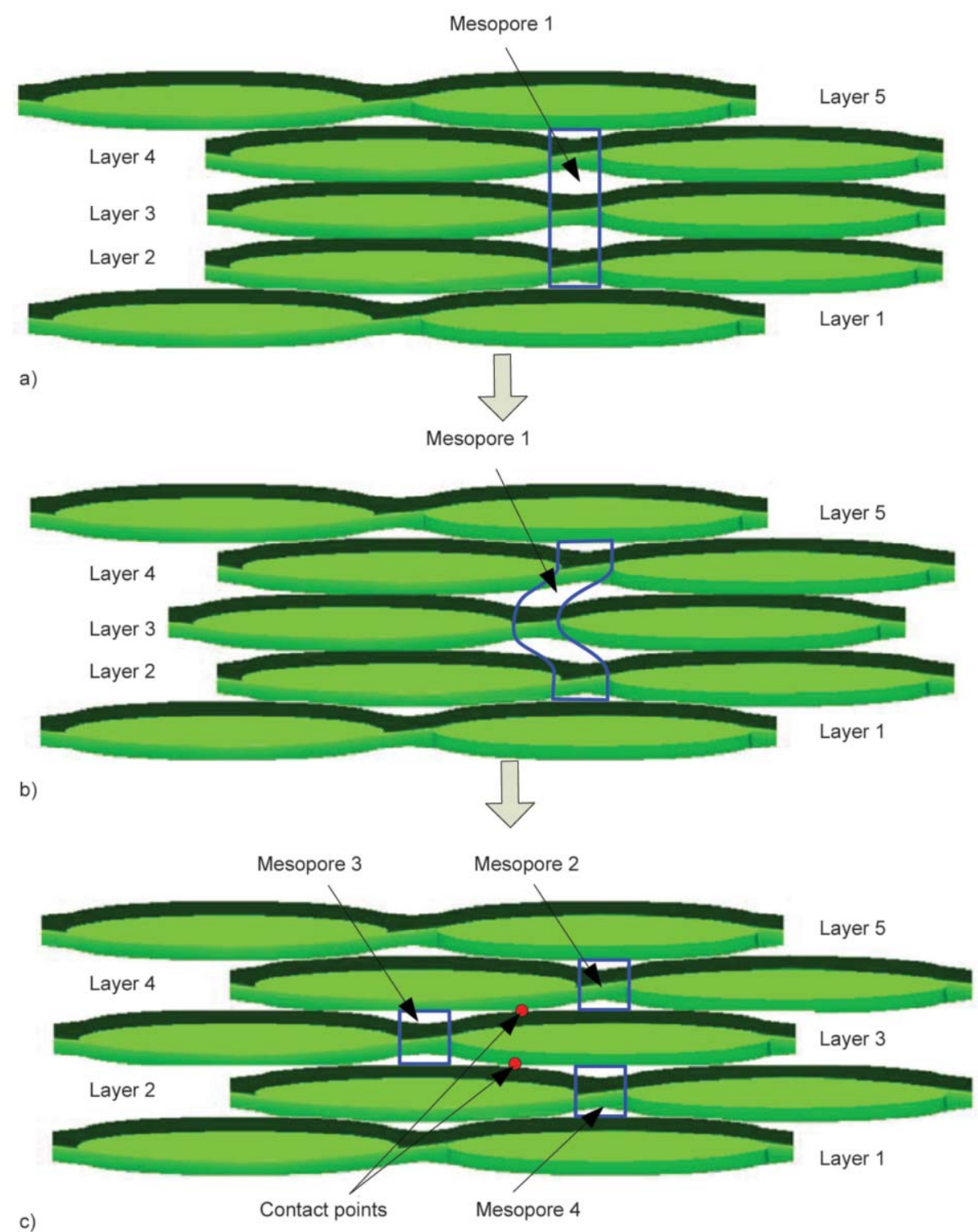

Figure 2. Effect of in-plane relative shift on the through-thickness connection of mesopore I, a) a three-layer connected mesopore I, b) distortion of the connection path, c) breaking of the mesopore.

positions of contact points vary with the compaction state.

Figure 3 represents the effect of in-plane relative shift on the through-thickness connection of mesopore II. Mesopore I shown in Figure 3a is a twolayer connected mesopore II, its shape changes with the in-plane relative shift between Layer 1 and 2. When the relative shift is small, the shape of mesopore I will distort but maintain integrity as shown in Figure $3 b$. With the increase of relative shift, Layer 1 and 2 will contact with each other at the contact point shown in Figure 3c, and mesopore I will be broken into two disconnected mesopores, respectively are mesopore II and III. The position of contact point also varies with the compaction state.
During the through-thickness permeating of LCM, the formation processes of meso-scale-voids are shown in Figure 4, the dotted lines express the micro flow paths in yarns. When the global velocity of through-thickness resin flow is small, the micro flow velocity is larger than the meso flow velocity since the capillary wicking effect, which may cause the incomplete filling of mesopore when the micro flow fronts converge, then a meso-scale-void will be formed. Different types of mesopores have different pore shapes, pore sizes and micro flow paths, the parameters of air entrapment are different from each other as shown in Figure 4, so different models need to be established.

From the above analysis we can find that the height of mesopore is a key parameter for void formation 


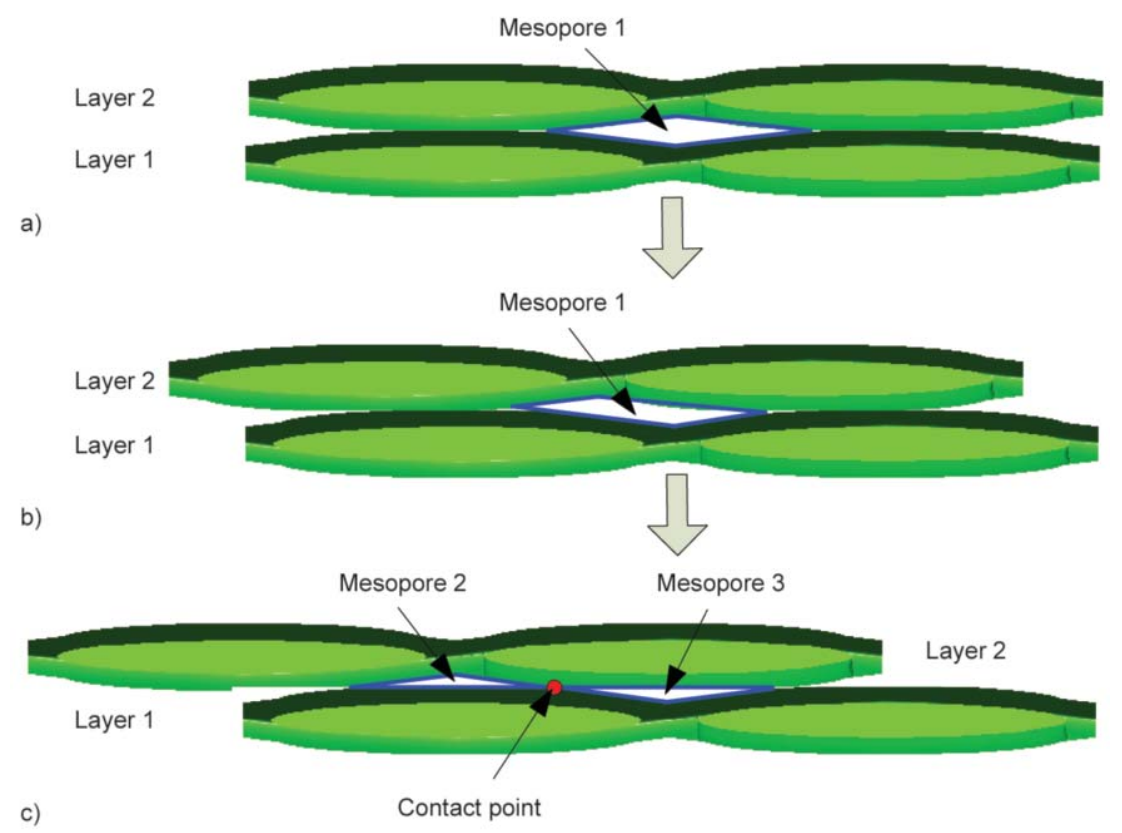

Figure 3. Effect of in-plane relative shift on the through-thickness connection of mesopore II, a) a two-layer connected mesopore II, b) distortion of the connection path, c) breaking of the mesopore.

prediction, which will be affected by the in-plane relative shift. When the relative shift is small as shown in Figure 2a, 2b and Figure 3a, 3b, the heights of the connected mesopores remain unchanged. While when the relative shift is large enough as shown in Figure 2c and Figure 3c, the connected mesopores will be bro-

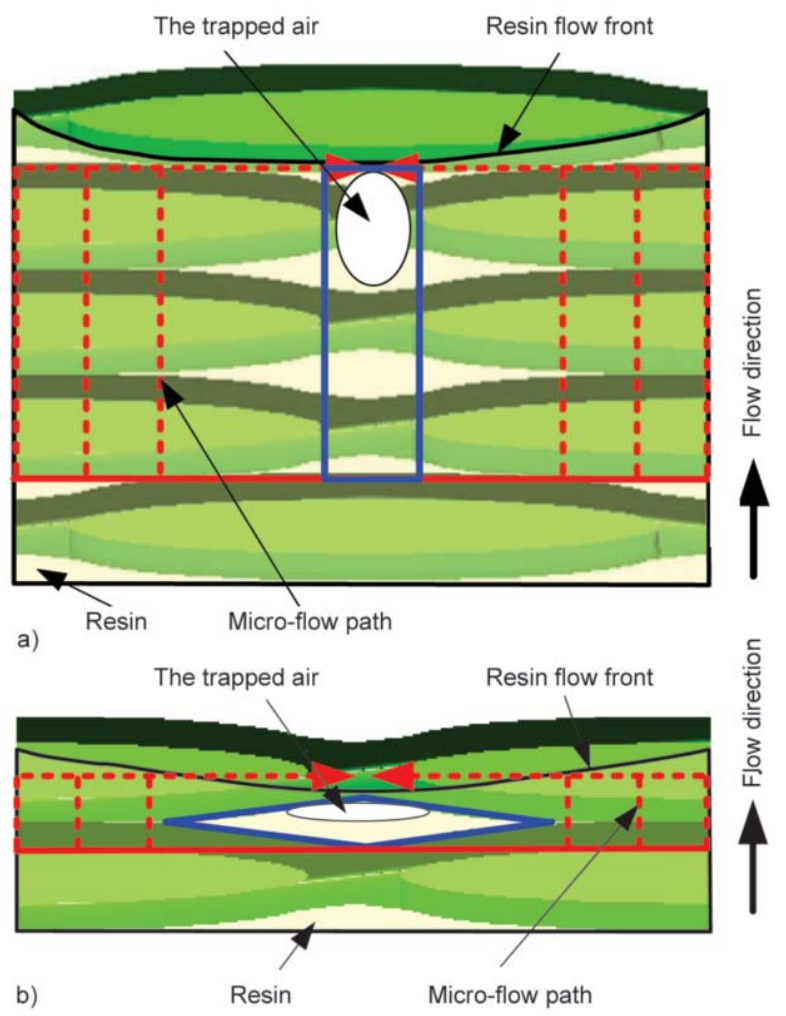

Figure 4. Formation processes of meso-scale-voids, (a) in mesopore I, (b) in mesopore II. ken into several disconnected mesopores, and their heights will be greatly decreased.

\section{Mathematical modeling of the meso-scale-void formation during through-thickness permeating}

\subsection{Meso and micro flow on the} through-thickness direction

As described above, resin flow in preform is composed by meso flow in mesopores and micro flow in micropores. According to the flow direction, micro flow can be divided into longitudinal flow and transversal flow.

In engineering practice, the through-thickness direction is generally consistent with gravity direction, the opposite direction of gravity is selected as the principal direction to build the flow model in this paper. For the meso flow, the capillary force can be ignored since the relatively large pore size, the Darcy's law as shown in Equation (2) is usually used to compute the flow velocity:

$u_{\mathrm{c}}=-\frac{1}{\phi_{\mathrm{c}}} \cdot \frac{K_{\text {unsat }}}{\mu} \cdot(\nabla p+\sigma g)$

where $u_{\mathrm{c}}$ is the meso flow velocity, $\phi_{\mathrm{c}}$ is the mesopore volume fraction which is obtained by dividing the volume of mesopores by the whole fabric volume, $p$ is pressure, $\sigma$ is the density of resin, $g$ is the gravitational acceleration, $K_{\text {unsat }}$ is the unsaturated permeability of preform which can be obtained by the 
regression analysis of measurement data of global flow front position with time.

For the micro flow, the effect of capillary force must be considered. Since the size of a meso-scale-void is much smaller than the global flow distance, we can assume that the global resin pressure gradient is identical in the mesopore and in the micropore and keeps unchanged during the void formation process. Therefore, Equation (3) can be used to compute the micro flow velocity:

$u_{\mathrm{t}}\left(K_{\mathrm{t}}, p_{\mathrm{c}}\right)=-\frac{1}{\phi_{\mathrm{t}}} \cdot \frac{K_{\mathrm{t}}}{\mu} \cdot\left(\nabla p+\sigma g-\frac{p_{\mathrm{c}}}{l_{\mathrm{s}}}\right)$

where $u_{\mathrm{t}}$ is the micro flow velocity, $K_{\mathrm{t}}$ is the permeability of yarn, which is either longitudinal permeability $K_{\mathrm{t}, 1}$ or transversal permeability $K_{\mathrm{t}, \mathrm{t}}, \phi_{\mathrm{t}}$ is the porosity of the yarn, $l_{\mathrm{s}}$ is the distance from the edge of the mesopore to the flow front, $p_{\mathrm{c}}$ is the capillary pressure, which can be the longitudinal capillary pressure $p_{\mathrm{c}, \mathrm{t}}$ or transversal capillary pressure $p_{\mathrm{c}, \mathrm{l}}$. The permeability of yarn can be obtained from empirical equations, such as the widely used Gebart model shown in Equation (4) [32]:

$$
\begin{aligned}
& K_{\mathrm{t}, \mathrm{l}}=\frac{8}{53} \frac{\left(1-v_{\mathrm{f}, \mathrm{t}}\right)^{3}}{v_{f, t}^{2}} r^{2} \\
& K_{\mathrm{t}, \mathrm{t}}=\frac{16}{9 \pi \sqrt{6}}\left(\sqrt{\frac{\nu_{\mathrm{f}_{\text {max }} \mathrm{t}}}{\nu_{\mathrm{f}, \mathrm{t}}}}-1\right)^{5 / 2} r^{2}
\end{aligned}
$$

where $v_{\mathrm{f}, \mathrm{t}}$ is the fiber volume fraction of yarn, $v_{\mathrm{f}_{\max }, \mathrm{t}}$ is the maximal volume fraction of yarn, $r$ is the radius of fiber.
The capillary pressure in Equation (3) can be calculated by Equations (5) and (6) [33]:

$$
\begin{aligned}
& p_{\mathrm{c}, \mathrm{t}}=\frac{\nu_{\mathrm{f}} \gamma}{2 \pi\left(1-\nu_{\mathrm{f}}\right)} \int_{-\pi / 2}^{\pi / 2} \frac{\cos (\theta+\eta)}{\sqrt{\frac{\pi}{2 \sqrt{3} v_{\mathrm{f}, \mathrm{t}}}-\cos \eta}} \mathrm{d} \eta \\
& p_{\mathrm{c}, \mathrm{l}}=\frac{2 \nu_{\mathrm{f}} \cdot \gamma \cos \theta}{r\left(1-v_{\mathrm{f}}\right)}
\end{aligned}
$$

where $\eta$ is the angular location of the resin-air meniscus during flow between neighboring fibers.

\subsection{Formation of meso-scale-void}

Figure 5 depicts the air entrapment process in mesopore I, the solid lines express the meso flow paths between yarns and the dotted lines express the micro flow paths in yarns. From the figure we can find that the move distance of meso flow front in the mesopore is $h_{\mathrm{f}}=n \cdot h$, the time required to impregnate the whole mesopore $\Delta t_{\mathrm{c}}$ can be computed by Equation (7):

$\Delta t_{\mathrm{c}}\left(h_{\mathrm{f}}\right)=\frac{h_{\mathrm{f}}}{u_{\mathrm{c}}}=-\frac{h_{\mathrm{f}}}{\frac{1}{\phi_{\mathrm{c}}} \cdot \frac{K_{\text {unstat }}}{\mu} \cdot(\nabla p+\sigma g)}$

As can be seen from Figure 5, the micro flow paths consist of two parts, the first part is the transversal micro flow on the through-thickness direction, the flow distance of this part is $h_{\mathrm{f}}$ which needs to be determined from the connectivity of the mosepores; the second part is either longitudinal or transversal micro flow on the in-plane direction, the flow distance of this part is $w_{\mathrm{f}} / 2$. As a result, the time required for micro flow fronts to envelop the mesopore I $\Delta t_{\mathrm{tI}}$ can be obtained by Equation (8):

$$
\Delta t_{\mathrm{tI}}=\left\{\begin{array}{l}
-\frac{h_{\mathrm{f}}}{\frac{1}{\phi_{\mathrm{t}}} \cdot \frac{K_{\mathrm{tt}}}{\mu} \cdot S}\left[1+\frac{p_{\mathrm{c}, \mathrm{t}}}{h_{\mathrm{f}} \cdot S} \ln \left(1-\frac{h_{\mathrm{f}} \cdot S}{p_{\mathrm{c}, \mathrm{t}}}\right)\right]-\frac{\frac{w_{\mathrm{f}}}{2}}{\frac{1}{\phi_{\mathrm{t}}} \cdot \frac{K_{\mathrm{t}, 1}}{\mu} \cdot S}\left[1+\frac{p_{\mathrm{c}, \mathrm{I}}}{\frac{w_{\mathrm{f}}}{2} \cdot S} \ln \left(1-\frac{\frac{w_{\mathrm{f}}}{2} \cdot S}{p_{\mathrm{c}, \mathrm{l}}}\right)\right], \\
\text { The horizontal flow direction is parallel with the yarn axis } \\
-\frac{h_{\mathrm{f}}+\frac{w_{\mathrm{f}}}{2}}{\frac{1}{\phi_{\mathrm{t}}} \cdot \frac{K_{\mathrm{tt}}}{\mu} \cdot S}\left[1+\frac{p_{\mathrm{c}, \mathrm{t}}}{\left(h_{\mathrm{f}}+\frac{w_{\mathrm{f}}}{2}\right) \cdot S} \ln \left(1-\frac{\left(h_{\mathrm{f}}+\frac{w_{\mathrm{f}}}{2}\right) \cdot S}{p_{\mathrm{c}, \mathrm{t}}}\right)\right],
\end{array}\right.
$$

The horizontal flow direction is perpendicular to the yarn axis

where $S=\nabla p+\rho g$. If $\Delta t_{\mathrm{c}}<\Delta t_{\mathrm{t}}$, the mesopore I will be filled by meso flow before it is enveloped by micro flow, no meso-scale-void will be generated; if $\Delta t_{\mathrm{c}}>\Delta t_{\mathrm{t}}$, some air will be entrapped in the mesopore by micro flow, a meso-scale-void will be formed and its height $h_{\mathrm{v}}$ can be calculated by Equation (9):

$$
h_{\mathrm{v}}=h_{\mathrm{f}}-\int_{0}^{\Delta t_{\mathrm{t}}} u_{\mathrm{c}} \mathrm{d} t
$$

Figure 6 shows the air entrapment process in mesopore II. The move distance of meso flow front in the mesopore is $h_{\mathrm{f}}=h / 2$, the time required to impregnate 


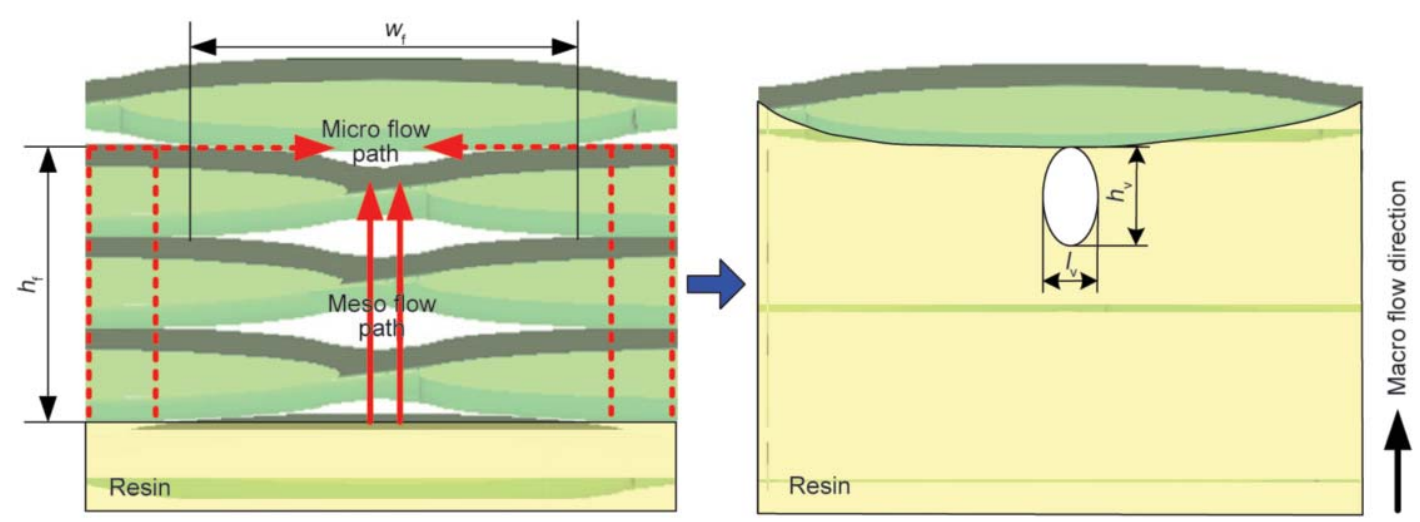

Figure 5. Air entrapment process in mesopore I.

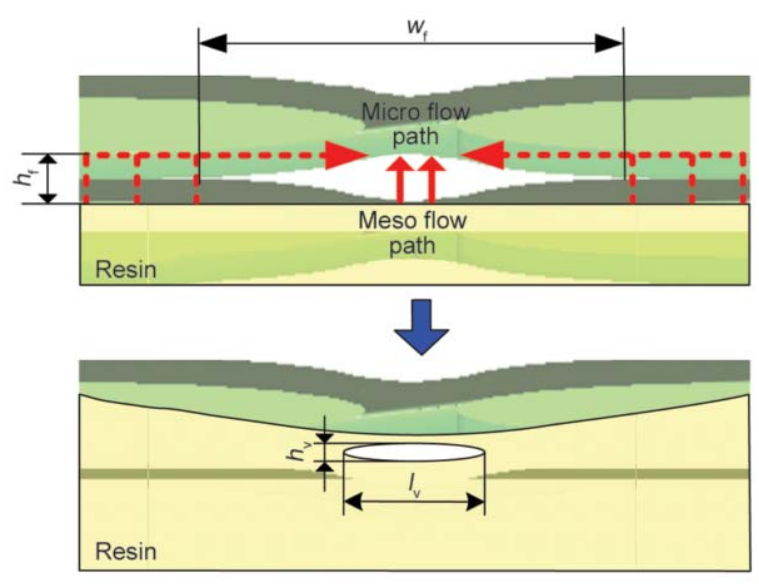

Figure 6 Air entrapment process in mesopore II.

the whole mesopore $\Delta t_{\mathrm{c}}$ can be obtained from Equation (7). From Figure 6 we can find that the micro flow paths also consist of two parts, the first part is the transversal micro flow on the through-thickness direction, the flow distance of this part is $h_{\mathrm{f}}$; the second part is half longitudinal micro flow and half transversal micro flow on the in-plane direction, the total flow distance of this part is $w_{\mathrm{f}}$. Therefore, the time required for flow fronts to envelop the mesopore II $\Delta t_{\text {tII }}$ can be obtained from Equation (10):

$$
\begin{aligned}
& \Delta t_{\mathrm{tII}}=-\frac{h_{\mathrm{f}}}{\frac{1}{\phi_{\mathrm{t}}} \cdot \frac{K_{\mathrm{tt}}}{\mu} S}\left[1+\frac{p_{\mathrm{c}, \mathrm{t}}}{h_{\mathrm{f}} \cdot S} \ln \left(1-\frac{h_{\mathrm{f}} \cdot S}{p_{\mathrm{c}, \mathrm{t}}}\right)\right]- \\
& -\frac{w_{\mathrm{f}}}{\frac{1}{\phi_{\mathrm{t}}} \cdot \frac{K_{\mathrm{t} t}+K_{\mathrm{t} .1}}{\mu} S}\left[1+\frac{K_{\mathrm{t} . \mathrm{t}} p_{\mathrm{c}, \mathrm{t}}+K_{\mathrm{t} .1} p_{\mathrm{c}, 1}}{w_{\mathrm{f}} \cdot\left(K_{\mathrm{t} . \mathrm{t}}+K_{\mathrm{t} .1}\right) \cdot S} \ln \left(1-\frac{w_{\mathrm{f}} \cdot\left(K_{\mathrm{t} . \mathrm{t}}+K_{\mathrm{t} . \mathrm{l}}\right) \cdot S}{K_{\mathrm{t} . \mathrm{t}} p_{\mathrm{c}, \mathrm{t}}+K_{\mathrm{t} .1} p_{\mathrm{c}, 1}}\right)\right]
\end{aligned}
$$

If $\Delta t_{\mathrm{c}}<\Delta t_{\mathrm{tII}}$, the mesopore II will be filled by meso flow before it is enveloped by micro flow, no mesoscale-void will be generated; if $\Delta t_{\mathrm{c}}>\Delta t_{\mathrm{tI}}$, air will be entrapped in the mesopore by micro flow, a mesoscale-void will be formed and its height hv can be calculated from Equation (9).
From Figure 5 we can find that the time of horizontal meso flow in mesopore I $\Delta t_{\mathrm{hI}}$ can be calculated by Equation (11):

$$
\Delta t_{\mathrm{hI}}=\left\{\begin{array}{l}
-\frac{\frac{w_{\mathrm{f}}}{2}}{\frac{1}{\phi_{\mathrm{t}}} \cdot \frac{K_{\mathrm{t} 1}}{\mu} \cdot S}\left[1+\frac{p_{\mathrm{c}, 1}}{\frac{w_{\mathrm{f}}}{2} \cdot S} \ln \left(1-\frac{\frac{w_{\mathrm{f}}}{2} \cdot S}{p_{\mathrm{c}, 1}}\right)\right], \\
\text { The horizontal flow direction is parallel } \\
\text { with the yarn axis } \\
-\frac{\frac{w_{\mathrm{f}}}{2}}{\frac{1}{\phi_{\mathrm{t}}} \cdot \frac{K_{\mathrm{tt}}}{\mu} \cdot S}\left[1+\frac{p_{\mathrm{c}, \mathrm{t}}}{\left(h_{\mathrm{f}}+\frac{w_{\mathrm{f}}}{2}\right) \cdot S} \ln \left(1-\frac{\left(h_{\mathrm{f}}+\frac{w_{\mathrm{f}}}{2}\right) \cdot S}{p_{\mathrm{c}, \mathrm{t}}}\right)\right], \\
\text { The horizontal flow direction is perpendicular } \\
\text { to the yarn axis }
\end{array}\right.
$$

Analogously, the time of horizontal meso flow in mesopore II $\Delta t_{\mathrm{hII}}$ can be computed by Equation (12) according to Figure 8:

$$
\begin{aligned}
& \Delta t_{\mathrm{hII}}=-\frac{w_{\mathrm{f}}}{\frac{1}{\phi_{\mathrm{t}}} \cdot \frac{K_{\mathrm{tt}}+K_{\mathrm{t} .1}}{\mu} S} . \\
& {\left[1+\frac{K_{\mathrm{t} . \mathrm{t}} p_{\mathrm{c}, \mathrm{t}}+K_{\mathrm{t} .1} p_{\mathrm{c}, \mathrm{l}}}{w_{\mathrm{f}} \cdot\left(K_{\mathrm{t} . \mathrm{t}}+K_{\mathrm{t} . \mathrm{l}}\right) \cdot S} \ln \left(1-\frac{w_{\mathrm{f}} \cdot\left(K_{\mathrm{t} . \mathrm{t}}+K_{\mathrm{t} .1}\right) \cdot S}{K_{\mathrm{t} . \mathrm{t}, \mathrm{t}} p_{\mathrm{c}}+K_{\mathrm{t} . \mathrm{l}} p_{\mathrm{c}, \mathrm{l}}}\right)\right]}
\end{aligned}
$$

So the length of the formed meso-scale-void $l_{\mathrm{v}}$ can be obtained by Equation (13):

$l_{\mathrm{v}}=w_{\mathrm{f}}-2 \cdot \int_{0}^{\Delta t_{\mathrm{h}}} u_{\mathrm{c}} \mathrm{d} t$ 
The width of the formed meso-scale-void wv can be determined using Equations (11)-(13) on the weft direction.

Assuming the formed meso-scale-void has an ellipsoidal shape, its volume $v_{\mathrm{v}}$ can be calculated by Equation (14):

$v_{\mathrm{v}}=\frac{\pi h_{\mathrm{v}} l_{\mathrm{v}} w_{\mathrm{v}}}{6}$

It should be noted that all the flow distances given above vary with the compaction state. The flow distances on the through-thickness direction can be easily obtained from the compaction rate, while the flow distance on the in-plane direction needs to be determined by the following method.

\subsection{Determination of $\boldsymbol{w}_{\mathrm{f}}$}

The flow distances on the in-plane direction $w_{\mathrm{f}}$ in Equations (8) to (13) depend on the positions of contact points between neighboring fabric layers as shown in Figure 7a, and the positions of contact points are determined by the contours of the interweaving region, which are similar to the cross-section of yarn since the tight interweaving between warp and weft according to Figure $7 b$, we assume

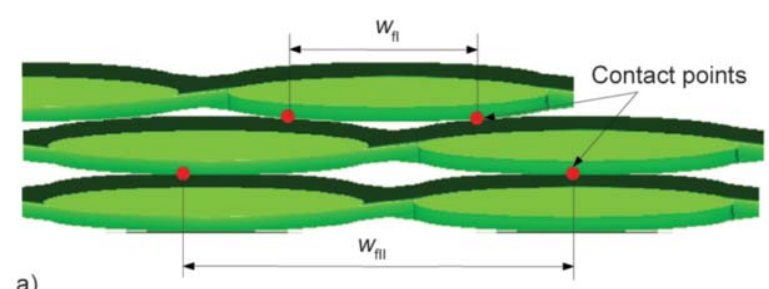

a)

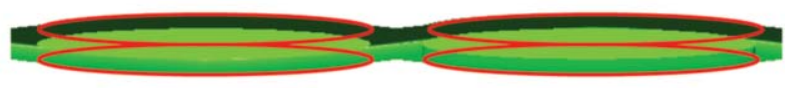

b)

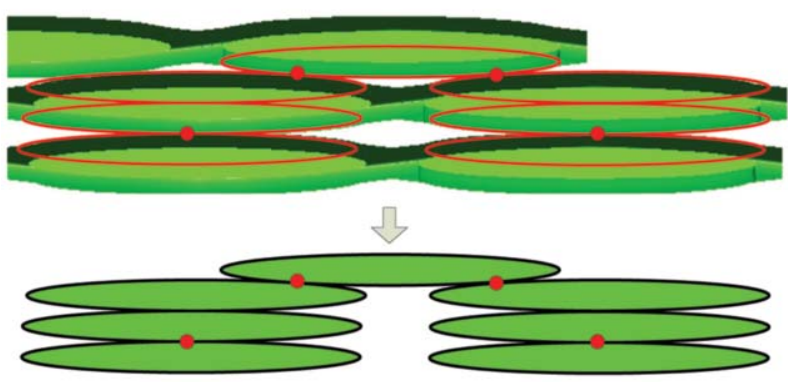

c)

Figure 7. Positions of contact points between neighboring fabric layers, a) contact points between neighboring fabric layers, $b$ ) contours of the interweaving region, c) contact points between cross-sections of yarns. that they are identical with each other in this paper, so the positions of contact points between neighboring fabric layers can be calculated approximately from the contact points between cross-sections of yarns as shown in Figure 7c.

Before mold-filling, fabrics are usually compressed to obtain the desired fiber content, during which we can assume that the yarn cross-section varies from ellipse to quasi-racetrack, and then racetrack with the increase of compression degree as shown in Figure 8 [34]. During the initial stage of compression, the width of the yarn $w_{\mathrm{t}}$ remains unchanged as the height of the yarn $h / 2$ decreases and the length of straight line $w_{\mathrm{s}}$ increases. When the cross-section of yarn becomes racetrack, $w_{\mathrm{t}}$ increases as $h / 2$ decreases.

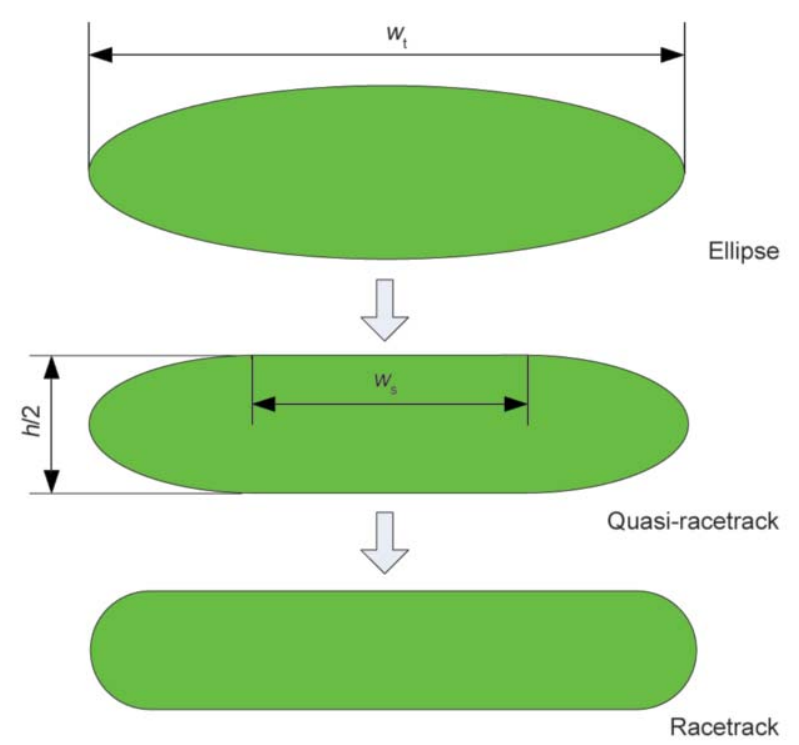

Figure 8. Variation of the cross-section shape of yarn.

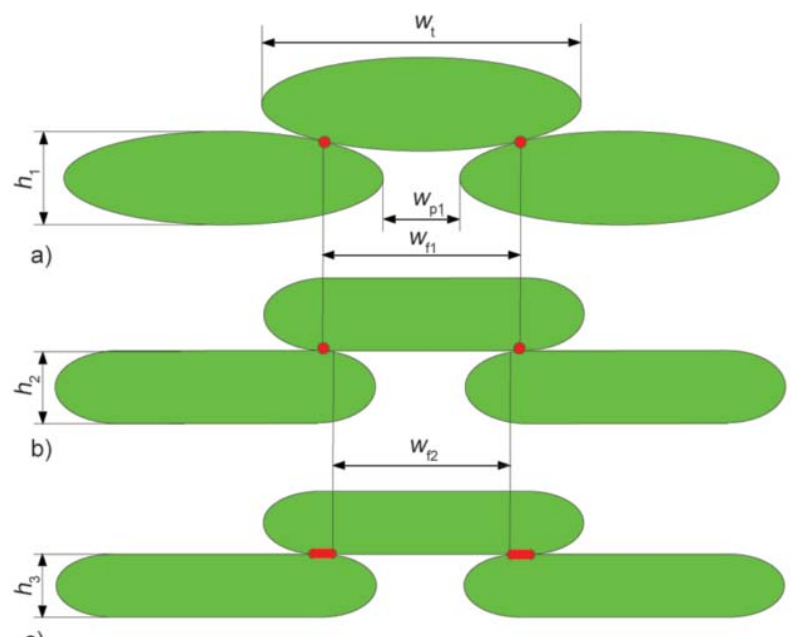

Figure 9. Changes of contact points and wf with compression rate of fabric, a) ellipse, b) quasi-racetrack, c) racetrack. 
Figure 9 demonstrates the changes of contact points and $w_{\mathrm{f}}$ with the compression rate of fabric, $h_{1}$ is the initial height of yarn, $h_{2}$ is the height of yarn at a specific amount of compression which will be analysed later, $h_{3}$ is the minimum height of yarn at the maximal amount of compression. In Figure 9a and $9 \mathrm{~b}$, the height of yarn decreases from $h_{1}$ to $h_{2}$, while the positions of contact points and wf remain unchanged. During this period, $w_{\mathrm{f}}$ is constant and can be computed by Equation (15):

$w_{\mathrm{f}}=w_{\mathrm{f} 1}=\frac{w_{\mathrm{t}}+w_{\mathrm{p} 1}}{2}, \quad h_{1} \leq \frac{h}{2} \leq h_{2}$

where $w_{\mathrm{p} 1}$ is the gap between adjacent yarns of a layer as shown in Figure 9a.

Continue to compress the fabric, when the height of yarn is smaller than $h_{2}$, line contact occurs between yarns as shown in Figure $9 \mathrm{c}$, in this case, $w_{\mathrm{f}}$ is given by Equation (16):

$$
\begin{aligned}
& w_{\mathrm{f}}=w_{\mathrm{f} 2}=\left\{\begin{array}{cc}
w_{\mathrm{f} 1}-\frac{(4-\pi)\left(\frac{h}{2}-h_{2}\right) w_{\mathrm{f} 1}+\pi\left(\frac{h}{2}-h_{2}\right) w_{\mathrm{t}}}{(4-\pi)\left(2 h_{2}-\frac{h}{2}\right)}, \\
\text { quasi-recetrack } \\
w_{\mathrm{p} 1}+\frac{h}{2}, & \text { racetrack }
\end{array}\right. \\
& h_{2}<\frac{h}{2} \leq h_{3}
\end{aligned}
$$

From the above analysis we can find that $h_{2}$ is a threshold of contact status between yarns, if the height of yarn is larger than $h_{2}$, point contact occurs and $w_{\mathrm{f}}$ can be obtained by Equation (14); otherwise, line contact occurs and wf needs to be computed by Equation (15). The threshold $h_{2}$ can be determined by Equation (17):

$h_{2}= \begin{cases}\frac{\pi h_{1} w_{\mathrm{t}}}{(\pi-4) w_{\mathrm{f} 1}+\pi h_{1} w_{\mathrm{t}}}, & \text { quasi-racerack } \\ w_{\mathrm{t}}-w_{\mathrm{f} 1}, & \text { racerack }\end{cases}$

\section{Experiments and discussions}

\subsection{Materials and equipment}

To verify the above proposed model, a series of experiments were carried out to measure the size of meso-scale-void formed during through-thickness permeating, and the effects of resin flow velocity and mesopore type were also analyzed.

The preform used is a glass plain fabric EWR600 (Hualike New Materials, Changzhou, China), its structure sizes of unit cell are shown in Table 1. The fiber volume fraction of yarn in EWR600 fabric is
Table 1. Geometric parameters of EWR600 fabric.

\begin{tabular}{|l|c|c|}
\hline \multicolumn{1}{|c|}{ Description } & Parameter & $\begin{array}{c}\text { Value } \\
{[\mathbf{m m}]}\end{array}$ \\
\hline Width of the warp yarns & $w_{\mathrm{t} 1}$ & 2.95 \\
\hline Thickness of the warp yarns & $h_{\mathrm{wa}}$ & 0.30 \\
\hline Gap between the warp yarns & $l_{\mathrm{p} 1}$ & 0.73 \\
\hline Width of the weft yarns & $w_{\mathrm{t} 2}$ & 3.24 \\
\hline Thickness of the weft yarns & $h_{\mathrm{we}}$ & 0.30 \\
\hline Gap between the weft yarns & $w_{\mathrm{p} 1}$ & 0.50 \\
\hline
\end{tabular}

$79 \%$, the average diameter of monofilament is $14 \mu \mathrm{m}$. According to Equation (4), the longitudinal permeability and transversal permeability of yarn are $K_{\mathrm{t}, 1}=$ $1.1 \cdot 10^{-13} \mathrm{~m}^{2}$ and $K_{\mathrm{t}, \mathrm{t}}=1.54 \cdot 10^{-14} \mathrm{~m}^{2}$, respectively. The test measurements showed that the fiber volume fraction of EWR600 fabric is $45.6 \%$, unsaturated through-thickness permeability is $2.86 \cdot 10^{-11} \mathrm{~m}^{2}$.

The resin system applied in experiments is the low viscosity E51 two-component epoxy resin YT-CC302 (Yituo Composites, Kunshan, China), the volume mixing ratio of resin and hardener is $2.8: 1$, the density of the mixture is $8 \mathrm{~g} / \mathrm{cm}^{3}$. The resin system used is the type of slow setting and its operable time is about 60-70 minutes. The viscosity and surface tension at room temperature of the resin system are respectively $0.25 \mathrm{~Pa} \cdot \mathrm{s}$ and $0.03 \mathrm{~N} / \mathrm{m}$ according to the measurements implemented by NDJ-8S rotational viscometer (Shanghai Precision Instrument Co. Ltd., Shanghai, China) and maximum bubble pressure
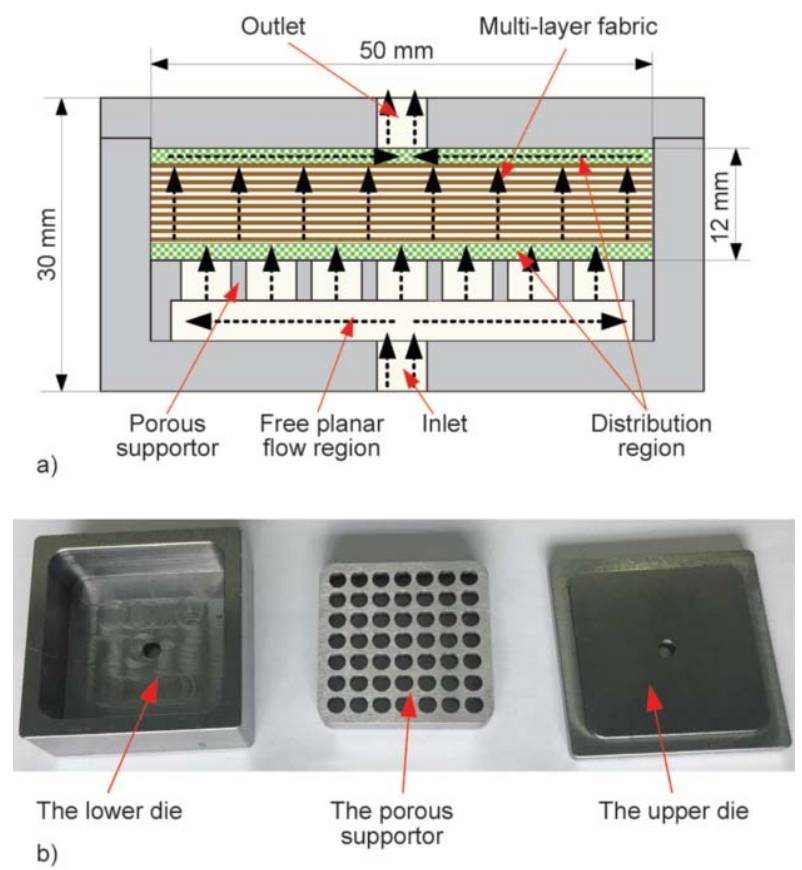

Figure 10. The mold used in experiments, (a) design of mold, (b) photographs of mold. 
method. The resin has a good wettability and its contact angle is set as $0^{\circ}$.

Design of mold used in experiments is shown in Figure 10a, both the upper and lower dies are made of metal, mold cavity is set on the lower die, inlet and outlet gates are set on the center of lower and upper dies, respectively. In order to form the one-dimensional through-thickness flow, a porous supportor is placed in the mold cavity. During mold-filling, resin tends to fill the gap below supportor firstly and then vertically flow upward to infiltrate the preform, as depicted by arrow dotted lines in Figure 10a. The cutting and lay-up of fabrics need to be accurately controlled to form the desired mesopore connection. Several layers of distribution medium need to be laid above and below the preform to ensure the flow uniformity. The photographs of the three parts of the mold are shown in Figure 10b.

Figure 11 shows the experiment equipment, constant flow rate injection at normal temperature and pressure was adopted, TJ-3A/W0109-1B constant flow injection pump from Longer Corporation (Baoding, China) was applied to control the resin flow velocity accurately and steadily. The upper die and lower die were clamped by two hand screw clamps. Silicone tubes were used to connect the syringe and inlet gate of mold.

After mold-filling, the mold with clamps was put together into a drying oven until the resin is fully cured. Then the mold was cutting by a milling machine, and the cross-section of the composite sample was obtained. The length, width and height of the meso-scale-voids formed in composite samples were measured by the super deep scene microscope VHX2000 (Keyence Corporation, Ōsaka, Japan) as shown in Figure 12, then the volume of the void can be calculated from Equation (14), five samples were made

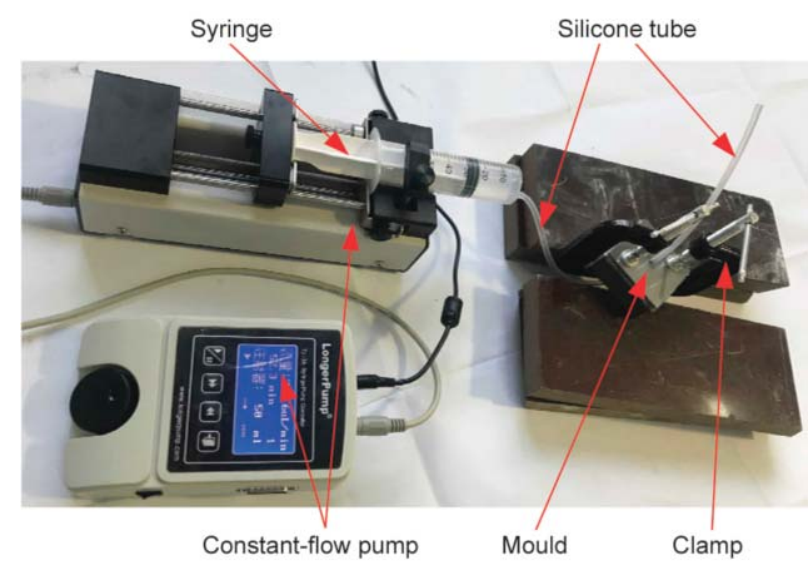

Figure 11. Experiment equipment.

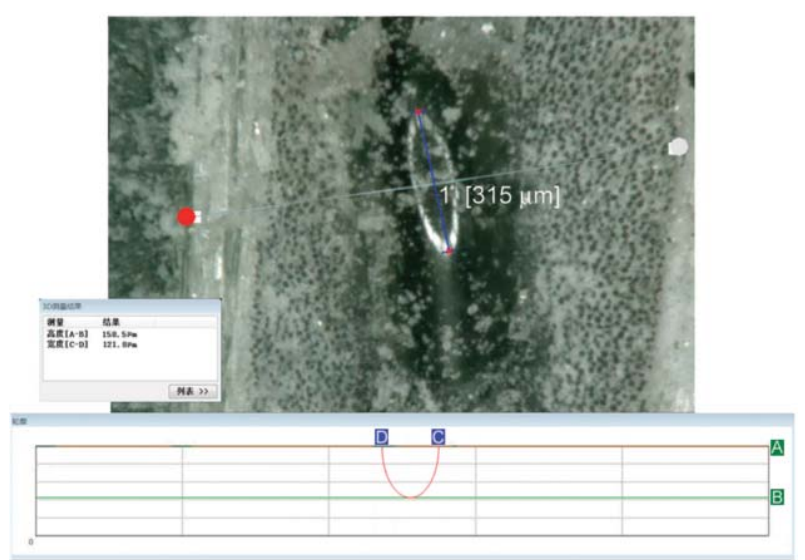

Figure 12. Measurement of meso-scale-void.

under each process condition, and twenty voids were measured for each sample to increase the accuracy of measurement results.

\subsection{Experiment results and discussions}

The heights of meso-scale-voids formed in mesopore I and mesopore II have been experimental measured. During the experiments of mesopore I, the cutting and lay-up of neighboring four fabric layers were controlled to obtain the two-layer connected mesopore as shown in Figure 13. Shown in Figure 14 is the change rule of meso-scale-void volume in mesopore I with the modified capillary number, in which the continuous curve and scatter dots represent the results obtained by Equation (8) and experiments, respectively. Since the constant flow rate injection was adopted in the experiments, the paramater $S$ used in Equations (8) and (10)-(12) was calculated approximately by $S=\mu \phi_{\mathrm{c}} u_{\mathrm{d}} / K_{\text {unsat }}$ according to Equation (2). The resin flow velocity of the experiments shown in Figure 14 are $4.4 \cdot 10^{-7}, 1.32 \cdot 10^{-6}, 2.2 \cdot 10^{-6}$, $3.08 \cdot 10^{-6} \mathrm{~m} / \mathrm{s}$, respectively. As can be seen from the figure, with the increase of modified capillary number which means the acceleration of macroscope

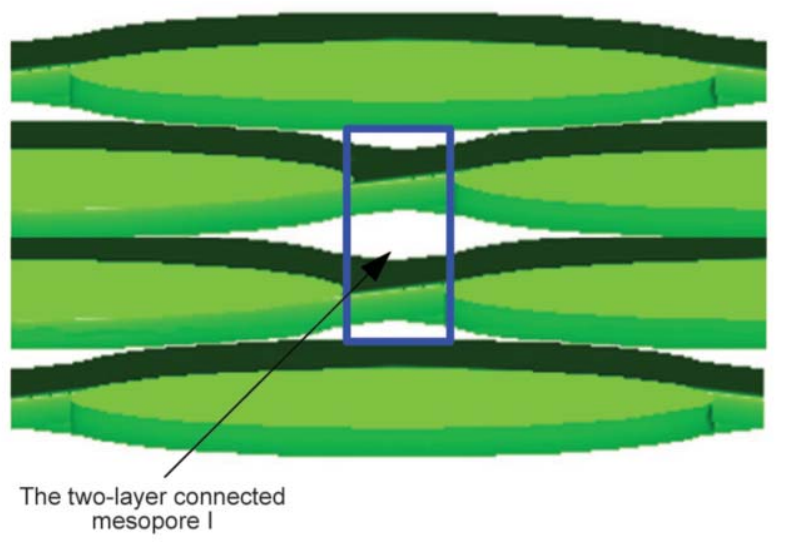

Figure 13. Two-layer connected mesopore I. 


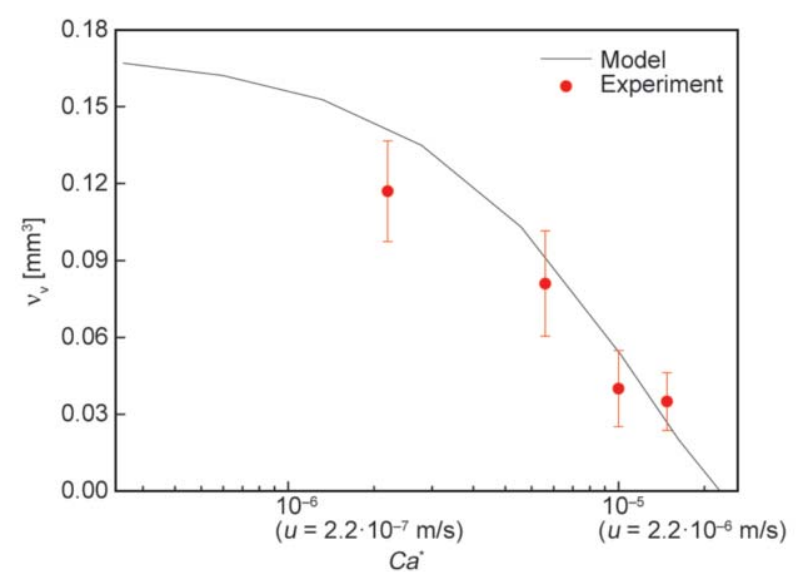

Figure 14. Change rule of meso-scale-void volume in mesopore I with the modified capillary number.

flow, the volume of meso-scale-void formed in mesopore I decreases gradually. This is because the increase of modified capillary number has little effect on micro flow velocity since its main driving force comes from capillary pressure. While the meso flow is primarily derived by hydrodynamic force, which is approximatively proportional to modified capillary number. Therefore, the increase of modified capillary number will produce a significant increase in mesopore infiltration, less air will be entrapped when the micro flow fronts converge, so the volume of the formed meso-scale-void decreases. The prediction results agree well with the experiment results, which demonstrates the correctness of the prediction model. The maximal error is about $35 \%$ and the standard deviations of experiment results are relatively large, which may be induced by the operation inconsistency during tailoring, lay-up and compaction of fabrics.

During the experiments of mesopore II, the cutting and lay-up of neighboring two fabric layers were controlled to obtain the mesopore II as shown in Figure 6.

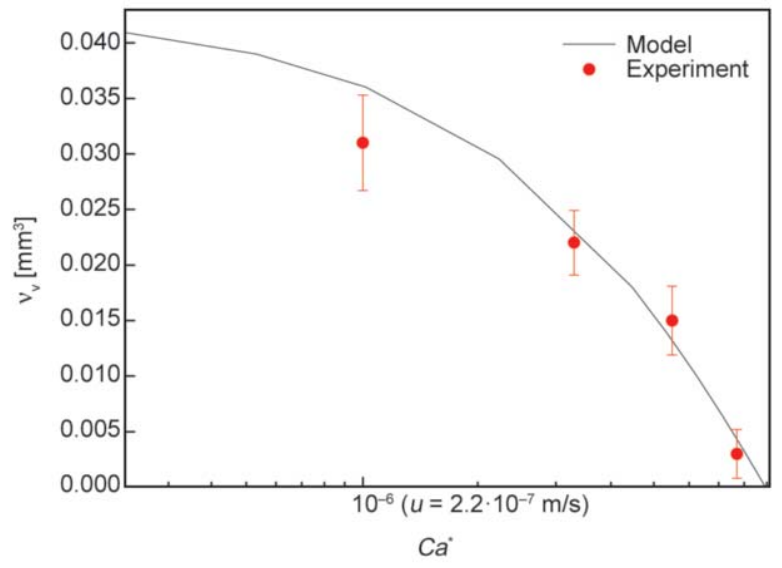

Figure 15. Change rule of meso-scale-void volume in mesopore II with the modified capillary number.
Figure 15 shows the change rule of meso-scale-void volume in mesopore II with the modified capillary number. The resin flow velocity of the experiments shown in Figure 15 are $2.2 \cdot 10^{-7}, 6.6 \cdot 10^{-7}, 1.1 \cdot 10^{-6}$, $1.54 \cdot 10^{-6} \mathrm{~m} / \mathrm{s}$, respectively. As observed in this figure, the volume of meso-scale-void formed in mesopore II also decreases with the increase of modified capillary number. The maximal error is about $33 \%$, larger standard deviation coefficient of experiment results in Figure 15 demonstrates that the condition control in the experiments of mesopore II has lower stability than the experiments of mesopore I.

From Figure 14 and Figure 15 we can find that most of the measurement results are smaller than the prediction values, which may be caused by the following reasons, (1) some air may escape along micro channels before the void is fully closed; (2) the shape and dimension of meso-scale-void may change with temperature, pressure and curing degree after its formation; (3) although the cutting positions were calculated and controlled carefully, it is difficult to precisely cut on the center of void, which will result in the reduction of the measured values.

The validity of the proposed model has been proved by the comparisons between prediction and experiment results, while we can find that manual operations during material preparation and void measurement bring large error and dispersion to the experimental results, the precise control of experimental conditions of void formation during through-thickness flow needs to be studied further. It needs to be noted that the model proposed in this paper is aimed at the through-thickness permeating type LCM process without vacuum supply, if vacuum degree is bigger than 0 , the volume of the formed void will proportionally decrease.

\section{Conclusions}

The analysis and prediction of void formation during through-thickness permeating type LCM, such as VARTM, CRTM and RFI are the foundation of process design and product quality control. However, present researches mainly focus on the void formation during in-plane flow, no study has been devoted to the void formation during through-thickness flow, which greatly hinders their application area. In this paper, the structural morphology and connectivity of mesopores in multi-layer woven fabrics have been analyzed, the difference between micro flow and meso flow paths during through-thickness permeating 
and its influence on void formation have been researched. Based on the modeling of micro flow and meso flow in multi-layer fabrics, a mathematical model has been established to predict the formation and size of meso-scale-void during through-thickness permeating, the variation of micro flow path with different compaction condition has also been analyzed to guarantee the precision of the model. The experiment mold and method for through-thickness flow were designed and a series of experiments have been implemented to explore the influence of moldfilling velocity and pore type on the size of mesoscale-void, the validity of the proposed model has been proved by the comparisons between prediction and experiment results.

\section{Acknowledgements}

The presented work was supported by the National Natural Science Foundation of China (grant number 51975074, 51605057); the Natural Science Foundation of Heilongjiang Province (grant number LH2019E080); the Fundamental Research Funds for the Central Universities (grant number 2018CDQYJX0013); the Postdoctoral Foundation Project of Chongqing (grant number Xm2016058).

\section{References}

[1] Godbole M. G., Purandare R., Harshe R., Hood A., Gururaja S., Joshi M., Advani S.: Influence of filament distribution on transverse tow permeability: Model predictions and experimental validation. Composites Part A: Applied Science and Manufacturing, 118, 150-161 (2019).

https://doi.org/10.1016/j.compositesa.2018.12.024

[2] Yoshida H. T., Ogasa T., Hayashi R.: Statistical approach to the relationship between ILSS and void content of CFRP. Composites Science and Technology, 25, 3-18 (1986).

https://doi.org/10.1016/0266-3538(86)90018-7

[3] Asadi A., Abusrea M. R., Arakawa K., Colton J., Kalaitzidou K.: A comparison of CFRP composite laminated joints fabricated with vacuum assisted resin transfer molding. Express Polymer Letters, 12, 781789 (2018).

https://doi.org/10.3144/expresspolymlett.2018.67

[4] Bowles K. J., Frimpong S.: Void effects on the interlaminar shear strength of unidirectional graphite-fiberreinforced composites. Journal of Composite Materials, 26, 1487-1509 (1992).

https://doi.org/10.1177/002199839202601006

[5] Olivier P., Cottu J. P., Ferret B.: Effects of cure cycle pressure and voids on some mechanical properties of carbon/epoxy laminates. Composites, 26, 509-515 (1995). https://doi.org/10.1016/0010-4361(95)96808-J
[6] Madsen B., Lilholt H.: Physical and mechanical properties of unidirectional plant fibre composites - An evaluation of the influence of porosity. Composites Science and Technology, 63, 1265-1272 (2003). https://doi.org/10.1016/S0266-3538(03)00097-6

[7] Park C. H., Lebel A., Saouab A., Bréard J., Lee W. I.: Modeling and simulation of voids and saturation in liquid composite molding processes. Composites Part A: Applied Science and Manufacturing, 42, 658-668 (2011).

https://doi.org/10.1016/j.compositesa.2011.02.005

[8] Rohatgi V., Patel N., Lee L. J.: Experimental investigation of flow-induced microvoids during impregnation of unidirectional stitched fiberglass mat. Polymer Composites, 17, 161-170 (1996).

https://doi.org/10.1002/pc.10601

[9] Park C. H., Lee W. I.: Modeling void formation and unsaturated flow in liquid composite molding processes: A survey and review. Journal of Reinforced Plastics and Composites, 30, 957-977 (2011). https://doi.org/10.1177/0731684411411338

[10] Gangloff J. J., Cender T. A., Eskizeybek V., Simacek P., Advani S. G.: Entrapment and venting of bubbles during vacuum bag prepreg processing. Journal of Composite Materials, 51, 2757-2768 (2016). https://doi.org/10.1177/0021998316676325

[11] Mahale A. D., Prud'Homme R. K., Rebenfeld L.: Quantitative measurement of voids formed during liquid impregnation of nonwoven multifilament glass networks using an optical visualization technique. Polymer Engineering and Science, 32, 319-326 (1992).

https://doi.org/10.1002/pen.760320504

[12] Lundstrom T. S., Gebart B. R., Lundemo C. Y.: Void formation in RTM. Journal of Reinforced Plastic Composites, 12, 1339-1349 (1993).

https://doi.org/10.1177/073168449301201207

[13] Lundström T. S., Gebart B. R.: Influence from process parameters on void formation in resin transfer molding. Polymer Composites, 15, 25-33 (1994).

https://doi.org/10.1002/pc.750150105

[14] Patel N., Rohatgi V., Lee L. J.: Micro scale flow behavior and void formation mechanism during impregnation through a unidirectional stitched fiberglass mat. Polymer Engineering and Science, 35, 837-851 (1995). https://doi.org/10.1002/pen.760351006

[15] Ruiz E., Achim V., Soukane S., Trochu F., Bréard J.: Optimization of injection flow rate to minimize micro/ macro-voids formation in resin transfer molded composites. Composites Science and Technology, 66, 475486 (2006).

https://doi.org/10.1016/j.compscitech.2005.06.013

[16] Leclerc J. S., Ruiz E.: Porosity reduction using optimized flow velocity in resin transfer molding. Composites Part A: Applied Science and Manufacturing, 39, 1859-1868 (2008).

https://doi.org/10.1016/j.compositesa.2008.09.008 
[17] LeBel F., Fanaei A. E., Ruiz É., Trochu F.: Prediction of optimal flow front velocity to minimize void formation in dual scale fibrous reinforcements. International Journal of Material Forming, 7, 93-116 (2014).

https://doi.org/10.1007/s12289-012-1111-x

[18] Ravey C., Ruiz E., Trochu F.: Determination of the optimal impregnation velocity in resin transfer molding by capillary rise experiments and infrared thermography. Composites Science and Technology, 99, 96-102 (2014). https://doi.org/10.1016/j.compscitech.2014.05.019

[19] Hu J., Liu Y., Shao X.: Study on void formation in multi-layer woven fabrics. Composites Part A: Applied Science and Manufacturing, 35, 595-603 (2004). https://doi.org/10.1016/j.compositesa.2003.11.007

[20] Lee D. H., Lee W. I., Kang M. K.: Analysis and minimization of void formation during resin transfer molding process. Composites Science and Technology, 66, 3281-3289 (2006).

https://doi.org/10.1016/j.compscitech.2005.07.008

[21] Schell J. S. U., Deleglise M., Binetruy C., Krawczak P., Ermanni P.: Numerical prediction and experimental characterisation of meso-scale-voids in liquid composite moulding. Composites Part A: Applied Science and Manufacturing, 38, 2460-2470 (2007). https://doi.org/10.1016/j.compositesa.2007.08.005

[22] Gourichon B., Deléglise M., Binetruy C., Krawczak P.: Dynamic void content prediction during radial injection in liquid composite molding. Composites Part A: Applied Science and Manufacturing, 39, 46-55 (2008). https://doi.org/10.1016/j.compositesa.2007.09.008

[23] Matuzaki R., Seto D., Naito M., Todoroki A., Mizutani Y.: Analytical prediction of void formation in geometrically anisotropic woven fabrics during resin transfer molding. Composites Science and Technology, 107, 154-161 (2015).

https://doi.org/10.1016/j.compscitech.2014.12.013

[24] Matuzaki R., Naito M., Seto D., Todoroki A., Mizutani Y.: Analytical prediction of void distribution and a minimum-void angle in anisotropic fabrics for radial injection resin transfer molding. Express Polymer Letters, 10, 860-872 (2016).

https://doi.org/10.3144/expresspolymlett.2016.80

[25] Yang B., Jin T., Bi F., Wei Y., Li J.: Influence of fabric shear and flow direction on void formation during resin transfer molding. Composites Part A: Applied Science and Manufacturing, 68, 10-18 (2015).

https://doi.org/10.1016/j.compositesa.2014.09.015
[26] Yang B., Zhao C. Y., Bi F. Y., Wang S. B., Ma C., Wang S. L.: Effect of horizontal shift between fabric layers on the meso-scale-void formation in liquid composite molding. Express Polymer Letters, 13, 501-511 (2019). https://doi.org/10.3144/expresspolymlett.2019.42

[27] DeValve C., Pitchumani R.: Simulation of void formation in liquid composite molding processes. Composites Part A: Applied Science and Manufacturing, 51, 22-32 (2013). https://doi.org/10.1016/j.compositesa.2013.03.016

[28] Arcila I. D. P., Power H., Londoño C. N., Escobar W. F. F.: Boundary element simulation of void formation in fibrous reinforcements based on the Stokes-Darcy formulation. Computer Methods in Applied Mechanics and Engineering, 304, 265-293 (2016).

https://doi.org/10.1016/j.cma.2016.02.010

[29] Patiño I. D., Power H., Nieto-Londoño C., Flórez W. F.: Stokes-Brinkman formulation for prediction of void formation in dual-scale fibrous reinforcements: A BEM/ DR-BEM simulation. Computational Mechanics, 59, 555-577 (2017). https://doi.org/10.1007/s00466-016-1360-5

[30] Nabovati A., Llewellin E. W., Sousa A. C. M.: Throughthickness permeability prediction of three-dimensional multifilament. Composites Part A: Applied Science and Manufacturing, 41, 453-463 (2010). https://doi.org/10.1016/j.compositesa.2009.11.011

[31] Yang B., Wang S., Wang Y.: Effect of nesting in laminates on the through-thickness permeability of woven fabrics. Applied Composite Materials, 25, 1237-1253 (2018). https://doi.org/10.1007/s10443-018-9699-8

[32] Gebart B. A.: Permeability of unidirectional reinforcements for RTM. Journal of Composite Materials, 26, 1100-1133 (1992). https://doi.org/10.1177/002199839202600802

[33] Foley M. E., Gillespie J. W.: Modeling the effect of fiber diameter and fiber bundle count on tow impregnation during liquid molding processes. Journal of Composite Materials, 39, 1045-1065 (2005). https://doi.org/10.1177/0021998305048739

[34] Yang B., Wang S., Tang Q.: Geometry modeling and permeability prediction for textile preforms with nesting in laminates. Polymer Composites, 39, 4408-4415 (2018). https://doi.org/10.1002/pc.24526 